\title{
IMPLEMENTASI CEDERA AKIBAT KECELAKAAN KERJA PERAWAT DI INTANSI KESEHATAN
}

\author{
Miranda Sipayung \\ miranda.sipayung068@gmail.com
}

\section{Latar Belakang}

Rumah sakit adalah sebuah industri jasa tempat penyediaan layanan kesehatan untuk masyarakat dan rumah sakit merupakan salah satu tempat kerja yang berpotensi menimbulkan bahaya. Kejadian penyakit infeksi di rumah sakit dianggap sebagai suatu masalah serius karena mengancam kesehatan dan kesejahteraan pasien dan petugas kesehatan secara global (Luo, et all, 2010).

Kecelakaan kerja menjadi salah satu masalah urgen di lingkungan rumah sakit. Hal ini diakibatkan karena rumah sakit merupakan suatu unit pelayanan kesehatan yang memberikan pelayanan pada semua bidang dan jenis penyakit. Oleh sebab itu rumah sakit dituntut untuk dapat menyediakan dan menerapkan suatu upaya agar semua sumber daya manusia yang ada di rumah sakit dapat terlindungi, baik dari penyakit maupun kecelakaan akibat kerja (Ivana, Widjasena \& Jayanti, 2014). Pemerintah melakukan berbagai upaya untuk mengatasi kecelakaan kerja di rumah sakit, salah satunya dengan dikeluarkannya Undang-Undang Nomor 23 Tahun 1992 dan Undang-Undang Nomor 36 Tahun 2009 tentang penerapan Kesehatan dan Keselamatan Kerja di rumah sakit. Kecelakaan kerja pada perawat dianggap sebagai suatu masalah serius karena mengancam kesehatan dan kesejahteraan pasien dan petugas Kesehatan secara global (Maria, 2015). Kecelakaan tersebut yang pada akhirnya dapat mempengaruhi produktivitas kerja perawat. Produktivitas kerja yang rendah pada akhirnya berdampak terhadap pelayanan kesehatan yang diberikan oleh rumah sakit.

Keselamatan dan kesehatan kerja merupakan hal penting yang harus diterapkan di semua tempat kerja, baik pada sektor formal maupun sektor informal. Terlebih bagi tempat kerja yang memiliki risiko atau bahaya yang tinggi, serta dapat menimbulkan kecelakaan kerja maupun penyakit akibat kerja. keselamatan dan kesehatan kerja seharusnya diterapkan pada semua pihak yang terlibat dalam proses kerja, mulai dari tingkat manager sampai dengan karyawan biasa. Berdasarkan Undang-Undang No. 1 Tahun 1970 yang menyatakan bahwa setiap tenaga 
kerja memiliki hak untuk mendapat perlindungan bagi keselamatannya dalam melakukan pekerjaan untuk kesejahteraan hidup dan meningkatkan produksi serta produktivitas Nasional.

\section{METODE}

Metode yang digunakan dalam kajian Perumusan diagnosa keperawatan dalam mencapai asuhan keperawatan ini menggunakan metode pengumpulan data dengan menggunakan literature review berdasarkan teks buku,buku referensi,jurnal (10 tahun terakhir) dengan menganalisis dan membaca setiap sumber literature berkenaan dengan topik materi yang sedang dibahas untuk mendapatkan berbagai informasi yang lengkap dan akurat dengan cara menyimpulkannya dari literature review yang ada.

\section{HASIL}

Berdasarkan hasil dari setiap literature review yang saya dapatkan, yaitu seperti buku teks,jurnal atau buku referensi lainnya bahwasanya Peningkatan kepatuhan perawat dalam melaksakan prosedur kerja dapat dilakukan dengan cara meningkatan kesadaran perawat untuk bertindak aman dalam upaya meningkatkan keselamatan dan kesehatan saat bekerja. Kesadaran perawat dapat ditumbuhkan dengan cara pelatihanpelatihan guna meningkatkan pengetahuan perawat mengenai keselamatan dan kesehatan kerja dan juga pengetahuan mengenai bahaya kerja pada perawat sehingga perawat secara mandiri dapat berperilaku aman saat bekerja. Bagi perawat agar tetap berupaya meminimalkan faktorfaktor pemungkin dan membekali dirinya dengan meningkatkan pengetahuan melalui seminar, media internet atau buku guna mendapatkan informasi terbaru tentang K3 sehingga dalam menerapkan asuhan keperawatan selalu memperhatikan budaya kerja K3 secara aman dengan penekanan pada universal precautions.

Untuk dapat bekerja secara aman dan nyaman, sangat dibutuhkan prosedur kerja. Prosedur kerja adalah petunjuk atau langkah-langkah kerja yang telah disusun sedemikian rupa sebagai panduan bagi tenaga kerja dalam melakukan pekerjaan. Prosedur kerja disusun dengan tujuan agar para pekerja dapat melakukan pekerjaan dengan baik dan benar, agar dapat menghasilkan pekerjaan yang baik pula, serta terhindar dari berbagai bahaya atau risiko yang dapat terjadi di lingkungan kerja.

Untuk mencegah terjadinya kecelakaan atau penyakit akibat kerja adalah melakukan pengendalian terhadap risiko tersebut. Pengendalian yang sudah dilakukan oleh pihak perusahaan adalah menyediakan alat pelindung diri berupa masker, sarung tangan, dan sepatu boot. Penggunaan APD memang sering di pilih sebagai pengendalian bahaya untuk 
mengurangi atau mencegah terjadinya kecelakaan kerja ataupun penyakit akibat kerja. Hasil penelitian tentang pengaruh pemakaian APD terhadap kejadian kecelakaan kerja menunjukkan bahwa kepatuhan atau selalu menggunakan APD dapat membuat angka kejadian kecelakaan kerja semakin rendah. (Anggraini, 2011) Selain itu perusahaan juga melakukan pelatihan tentang housekeeping maupun K3 bagi petugas kebersihan.

\section{PEMAHASAN}

\section{Diagnosis Penyakit Akibat Kerja}

Secara teknis penegakan diagnosis dilakukan dengan cara berikut ini:2

1. Tentukan diagnosis klinis dengan anamnesis yang baik, pemeriksaan fisik diagnostik dan pemeriksaan penunjang.

2. Tentukan pajanan terhadap faktor risiko dengan melakukan anamnesis mengenai riwayat pekerjaan secara cermat dan teliti yang mencakup: Kapan pertama kali bekerja, sudah berapa lama bekerja, apa yang dikerjakan, bahan yang digunakan,informasi bahan yang digunakan (Material Safety Data Sheet/MSDS), bahan yang diproduksi, jenis bahaya yang ada, jumlah pajanan, kapan mulai timbul gejala, kejadian sama pada pekerja lain, pemakaian alat pelindung diri, cara melakukan pekerjan, pekerjaan lain yang dilakukan,kegemaran (hobi) dan kebiasaan lain (merokok, alkohol)

3. Membandingkan gejala penyakit sewaktu bekerja dan dalam keadaan tidak bekerja.

- Pada saat bekerja maka gejala timbul atau menjadi lebih berat, tetapi pada saat tidak bekerja atau istirahat maka gejala berkurang atau hilang

- Perhatikan juga kemungkinan pemajanan di luar tempat kerja

- Informasi tentang ini dapat ditanyakan dalam anamnesis atau dari data penyakit di perusahaan

4. Pemeriksaan fisik yang dilakukan dengan catatan :

- Tanda dan gejala yang muncul mungkin tidak spesifik

- Pemeriksaan laboratorium penunjang membantu diagnostik klinis

- Dugan adanya penyakit akibat kerja dilakukan juga melalui pemeriksaan laboratorium khusus atau pemeriksaan biomedis

5. Pemeriksaan laboratorium khusus atau pemeriksaan biomedis 
- Seperti pemeriksaan spirometri dan rontgen paru (pneumokoniosispembacaan standar ILO)

- Pemeriksaan audiometrik

- Pemeriksaan hasil metabolit dalam darah atau urin

6. Pemeriksaan atau pengujian lingkungan kerja atau data hygiene perusahaan yang memerlukan:

- Kerja sama dengan tenaga ahli hygiene perusahaan

- Kemampuan mengevaluasi faktor fisik dan kimia berdasarkan data yang ada

- Pengenalan secara langsung sistem kerja, intensitas dan lama pemajanan

7. Konsultasi keahlian medis dan keahlian Lain

- Seringkali penyakit akibat kerja ditentukan setelah ada diagnosis klinis, kemudian dicari faktor penyebabnya di tempat kerja atau melalui pengamatan (penelitian) yang relatif lebih lama

- Dokter spesialis lainnya, ahli toksikologi dan dokter penasihat (kaitan dengan kompensasi)

\section{Pencegahan}

Berikut ini adalah penerapan konsep lima tingkatan pencegahan penyakit (five level of prevention disease) pada penyakit akibat kerja, yakni:2,4

a. Peningkatan kesehatan (health promotion). Misalnya: penyuluhan kesehatan dan keselamatan kerja (K3) pendidikan kesehatan, meningkatkan gizi yang baik, pengembangan kepribadian, perusahaan yang sehat dan memadai, rekreasi, lingkungan kerja yang memadai, penyuluhan perkawinan dan pendidikan seksual, konsultasi tentang keturunan dan pemeriksaan kesehatan periodik.

b. Perlindungan khusus (specific protection). Misalnya: imunisasi, hygiene perorangan, sanitasi lingkungan, serta proteksi terhadap bahaya dan kecelakaan kerja dengan menggunakan alat pelindung diri (APD) seperti helm, kacamata kerja, masker, penutup telinga (ear muff dan ear plug) baju tahan panas, sarung tangan, dan sebagainya.

c. Diagnosis (deteksi) dini dan pengobatan segera serta pembatasan titik-titik lemah untuk mencegah terjadinya komplikasi. 
d. Membatasi kemungkinan cacat (disability limitation). Misalnya: memeriksa dan mengobati tenaga kerja secara komprehensif, mengobati tenaga kerja secara sempurna dan pendidikan kesehatan.

e. Pemulihan kesehatan (rehabilitation). Misalnya: rehabilitasi dan mempekerjakan kemali para pekerja yang menderita cacat. Sedapat mungkin perusahaan mencoba menempatkan keryawan-karyawan cacat di jabatan yang sesuai.

\section{Upaya yang dapat dilakukan oleh perusahaan untuk mencegah PAK adalah sebagai berikut:}

1. Menyingkirkan atau mengurangi risiko pada sumbernya, misalnya menggantikan bahan kimia yang berbahaya dengan bahan yang tidak berbahaya.

2. Mengurangi risiko dengan pengaturan mesin atau menggunakan APD.

3. Menetapkan prosedur kerja secara aman untuk mengurangi risiko lebih lanjut.

4. Menyediakan, memakai dan merawat APD

Kecelakaan adalah kejadian tidak terduga yang disebabkan oleh tindakan tidak aman dan kondisi tidak aman (Heinrich, 1930). Sebagian besar (85\%) kecelakaan disebabkan oleh faktor manusia dengan tindakan yang tidak aman.

Tindakan tidak aman (unsafe action)adalah tindakan yang dapat membahayakan pekerja itu sendiri maupun orang lain yang dapat menyebabkan terjadinya kecelakaan yang dapat disebabkan oleh berbagai hal seperti tidak memakai APD, tidak mengikuti prosedur kerja, tidak mengikuti peraturan keselamatan kerja dan bekerja tidak hati-hati, dimana dari setiap 300 tindakan tidak aman, akan terjadi 1 (satu) kali kecelakaan yang mengakibatkan kehilangan hari kerja.

\section{Pengurangan Risiko Pasien Jatuh}

Rumah sakit mengembangkan suatu pendekatan untuk mengurangi risiko pasien dari cedera karena jatuh. Jumlah kasus jatuh cukup bermakna sebagai penyebab cedera bagi pasien rawat inap. Dalam konteks masyarakat yang dilayani, pelayanan yang disediakan, dan fasilitasnya rumah sakit perlu mengevaluasi risiko pasien jatuh dan mengambil tindakan untuk mengurangi risiko cedera bila sampai jatuh. Evaluasi bisa termasuk riwayat jatuh, obat dan telaah pasien yang bermkemungkinan mengkonsumsi alkohol, gaya jalan dan keseimbangan, serta alat bantu 
berjalan yang digunakan oleh pasien. Elemen yang menjadi penilaian sasaran VI adalah sebagai berikut.

1. Melakukan pengkajian risiko jatuh pada pasien yang dirawat di rumah sakit.

2. Melakukan tindakan untuk mengurangi atau menghilangkan risiko jatuh.

3. Memberikan tanda bila pasien berisiko jatuh dengan gelang warna kuning dan kode jatuh yang telah ditetapkan oleh manajemen

\section{Tujuan Sistem Keselamatan Pasien}

Tujuan penerapan sistem keselamatan pasien di rumah sakit antara lain:

1. Terciptanya budaya keselamatan pasien dirumah sakit

2. Meningkatnya akuntabilitas rumah sakit terhadap pasien dan masyarakat.

3. Menurunnya Kejadian Tak Diharapkan (KTD)

4. Terlaksananya program pencegahan sehingga tidak terjadi pengulangan KTD

Dalam upaya pencapaian tujuan keselamatan pasien ini, setiap rumah sakit wajib melaksanakan sistem keselamatan pasien melalui upaya- upaya sebagai berikut:

1. Akselerasi program infeksion control prevention (ICP)

2. Penerapan standar keselamatan pasien dan pelaksanaan 7 langkah menuju keselamatan pasien rumah sakit. Dan di evaluasi melalui akreditasi rumah sakit

3. Peningkatan keselamatan penggunaan darah (blood safety).

4. Dievaluasi melalui akreditasi rumah sakit.

5. Peningkatan keselamatan pasien di kamar operasi cegah terjadinya wrong person, wrong site, wrong prosedure (Draft SPM RS:100\% tidak terjadi kesalahan orang, tempat, dan prosedur di kamar operasi)

6. Peningkatan keselamatan pasien dari kesalahan obat.

7. Pelaksanaan pelaporan insiden di rumah sakit dan ke komite keselamatan rumah sakit.

\section{DAFTAR PUSTAKA}


ARDENNY.(2015). FAKTOR YANG BERHUBUNGAN DENGAN KECELAKAAN KERJA PADA PERAWAT DI RUMAH SAKIT JIWA TAMPAN PEKANBARU TAHUN 2015. Jurnal Proteksi Kesehatan, 4(1),1-6

Hanifa,N.,D. (2017). Hubungan Pengetahuan dengan Upaya Penerapan K3 pada Perawat. Bandung Meeting on Global Medicine \& Health (BaMGMH), 1(1)

Kun Dwi Apriliawati, Ekawati, B. K. (2017). Efektivitas Pelaksanaan Manajemen Organisasi Keselamatan dan Kesehatan Kerja Rumah Sakit (K3RS) Di Rumah Sakit X Semarang.

Nazirah,R., Yuswardi. (2017). PERILAKU PERAWAT DALAM PENERAPAN MANAJEMENKESEHATAN DAN KESELAMATAN KERJA (K3) DI ACEH. Idea Nursing Jpurnal , 8 (3) , 2580- 2445

Salawati,L. (2015). PENYAKIT AKIBAT KERJA DAN PENCEGAHAN. JURNAL KEDOKTERAN SYIAH KUALA,15 (2)

Simamora, R. H. (2017). A strengthening of role of health cadres in BTA-Positive Tuberculosis (TB) case invention through education with module development and video approaches in Medan Padang bulan Comunity Health Center, North Sumatera Indonesia. International Journal of Applied Engineering Research, 12(20), 10026-10035.

Simamora, R. H., \& Saragih, E. (2019). Penyuluhan kesehatan terhadap masyarakat: Perawatan penderita asam urat dengan media audiovisual. JPPM (Jurnal Pendidikan dan Pemberdayaan Masyarakat), 6(1), 24-31.

Silvia Maria P J.dkk.2015. KEJADIAN KECELAKAAN KERJA PERAWAT BERDASARKAN TINDAKAN TIDAK AMAN . Jurnal Care Vol. 3, No. 2

Sucipto, D. C. (2014).Keselamatan Dan Kesehatan Kerja. Yogyakarta: Gosyeng Publisher.

Sunandar, Ibrahim. H, Damayanti,S.D, A.(2017). Gambaran Penerapan Standart Keselamatan dan Kesehatan Kerja Rumah Sakit Umum Daerah Haji Makassar, Public Health Science Journal, 9(2), 160-173. Universitas Islam Negeri Alauddin Makassar.

Tukatman., Sulistiawati,,Purwaningsih.,\& Nursalam. (2015). ANALISIS KESELAMATAN DAN KESEHATAN KERJA PERAWAT DALAM PENANGANAN PASIEN DI RUMAH SAKIT BENYAMIN GULUH KABUPATEN KOLAKA. Jurnal Ners, 10 (2),343-347 
Yuantari, MG Catur \& Hafizhatun Nadia. 2018 Analisis Risiko Keselamatan dan Kesehatan Kerja Pada Petugas Kebersihan di Rumah Sakit. Faletehan Health Journal,5 (3) (2018) 107116. ISSN 2088-673X| e-ISSN 2597-8667 